\title{
Extended exponence in isiNdebele morphology
}

\author{
Mbulisi Ndlovu \\ Department of Languages, Lupane State University, P.O. Box 170, Lupane, Zimbabwe \\ E-mail: mndlovu@1su.ac.zw \\ Progress Dube \\ Department of Languages, Lupane State University, P.O. Box 170, Lupane, Zimbabwe \\ E-mail: prdube@1su.ac.zw
}

\begin{abstract}
This article discusses extended exponence and headedness in the context of isiNdebele morphology. An attempt will be made to distinguish extended exponence from circumfixes. Headedness will be discussed in general, and how it is expressed in extended exponence. The main submission in this article is that isiNdebele has derivational and inflectional extended exponents, and that extended exponents are predominantly left-handed in nature. This assumption is founded on the premise that the terminal affixes of extended exponents can be done away with in some contexts. The study also establishes that morphological heads can either be right members of a word or left members.
\end{abstract}

Keywords: Extended exponence, circumfix, right-hand head rule, left-hand head rule.

\section{Introduction}

IsiNdebele is a Bantu language that belongs to the Nguni language family, and is spoken in Matabeleland and in some parts of Midlands in Zimbabwe. The term "isiNdebele" will be used in this article to refer to this language spoken in Zimbabwe. This paper focuses on headedness and extended exponence in isiNdebele. The aims of the paper are to investigate headedness in isiNdebele morphology in general, to discuss the notion of 'extended exponence', to identify types of extended exponents, and to ascertain whether extended exponents are left-headed or right-headed in isiNdebele. This article is made up of four sections: in section 1, we discuss extended exponence and circumfixes. Section 2 is a discussion of Williams' (1981) right-hand head rule and the criticism it has received. IsiNdebele data is used to test the applicability of this rule and the relevance of the criticism in relation to this data. Section 3 deals with isiNdebele data on extended exponence, and section 4 presents a summary of the whole discussion. 


\section{Extended exponents}

Realisation morphological theories are premised on the assumptions that a morphosyntactic property may be expressed by more than one morphological marker (Stump 2001: 4), and that "[...] an inflected word's individual inflectional markings may underdetermine the properties associated with the word as a whole" (Stump 2001: 7). The idea of extended exponence distinguishes realisation morphological theories from incremental morphological theories. In realisation morphological theories, exponents are morphological markers, and an exponent is said to be extended when its realisation is seen in at least two positions in a word form. Extended exponence characterises those instances of morphological realisation where a single morphosyntactic property seems to be expressed by more than one exponent in a word (Matthews 1974, Stump 2001, Müller 2006, Harris 2009, Cabello and Harris 2012). On a similar note, Kosch (2005: 166) posits that:

[e]xtended exponence describes the situation in which a single grammatical function or meaning is expressed by two or more morphological markers. These markers or exponents may be adjacent to each other, but they are normally separated from each other by intervening material.

This quote indicates that a single grammatical function can be marked by non-contiguous realisations in a word, although there are instances where the morphological realisations can be contiguous. If a morphological property is realised in a word by affixing $\mathrm{A} \ldots \mathrm{B}$ to a base $\mathrm{C}$ (i.e. ACB) such that either AC or $\mathrm{CB}$ are complete words, we can say that $\mathrm{A}$... B is an extended exponent. The implication here is that, although the prefixal element and the suffixal element appear as if they are always interdependent, there are instances where the one element can occur in the absence of the other.

\section{Circumfixes}

A circumfix is made up of a prefix and a suffix, and these latter two are simultaneously affixed to a base (Marušič 2003). Mbah (2012) argues that "circumfixation is a process in which discontinuous affixes comprising two dissimilar parts surround an otherwise free morpheme". Parts of a circumfix are different from each other, non-contiguous, and are simultaneously affixed to a free morpheme. Kosch (2005) posits that circumfixation "describes the simultaneous affixation of a prefix and a suffix to a base to express a single meaning, category or process conjointly". Like extended exponents, the prefix and the suffix of a circumfix are discontinuous, different, and express the same morphosyntactic value. Rio-Torto (2002: 4) reiterates this by saying "[...] the aspectual properties related to the prefixed and suffixed constituents tend [in a circumfix] to have a mutual reinforcement, converging to the same or to complementary values". Similarities between extended exponents and circumfixes could be an indication that the two exist in a continuum. Linguists usually confuse circumfixes for extended exponents (Spencer 1991: 13). Kosch (2005: 166) contends that circumfixes are a type of extended exponence. The fundamental difference between the two is that the prefix and the suffix of a circumfix are mutually obligatory in all instances, whereas either a prefixal element or a suffixal element of the extended exponent can function in the absence of the other. Ruszkiewicz (2003: 160) defines a circumfix as a "[...] discontinuous affix X ... Y such that $\mathrm{XZY}$ is a complete word formed by affixing $\mathrm{X} \ldots \mathrm{Y}$ to some $\mathrm{Z}$ belonging to a specified category, and neither $\mathrm{XZ}$ nor $\mathrm{ZY}$ are words". Note that if $\mathrm{X} \ldots \mathrm{Y}$ in Ruszkiewicz's quotation is an extended exponent affixed to the base $\mathrm{Z}$ (i.e. $\mathrm{XZY}$ ), then $\mathrm{XZ}$ and $\mathrm{ZY}$ can be regarded as 
grammatical and acceptable words. This is due to the fact that, with extended exponence, either the prefix or the suffix can combine with a base to form an acceptable word.

\section{Right-Hand Head rule}

The Right-Hand Head rule (RHHr) is a morphological rule associated with generative morphology. The rule was proposed by Williams in 1981, and posits that in a word structure there is always a head morpheme. Williams (1981: 248) notes that, "in morphology, we define the head of a morphologically complex word to be the right-hand member of that word". Thus, the morpheme on the right of a word is the head of that particular structure. Taiwo (2009: 50) argues that the head of a word must be that which belongs to the same syntactic class of the word, and it must represent the core sense of the constructed word. Consequently, the assumption of the RHHr is that the right member of a word is the one that projects basic syntactic and semantic information in a complex word construction. The morphological heads can either be derivational or inflectional. Generally, the RHHr holds for some word constructions in isiNdebele. The following examples are instances of right-hand headedness in isiNdebele:

1

1.<smiles></smiles>

$$
\begin{aligned}
& \text { dobhiyane } \\
& \text { dobh-iyane } \\
& \text { pickvR-IDEO } \\
& \text { 'act of picking' }
\end{aligned}
$$

2. (i) dlithiza

dlith-z-a

act of biting IDEO-Verbalizer-FV

'bit violently'
3. (i) manzisa
manzi-s-a
waterNs-Verbalizer-FV
'make wet'

\section{(ii) fakiyane \\ fak-iyane \\ puFVR-IDEO \\ 'act of putting'}

(ii) hluthula

hluthu-1-a

act of snatching IDEO-Verbalizer-FV

'snatch'

(ii) gqilaza

gqil-az-a

slavens-Verbalizer-FV

'enslave'

The morphemes in bold in the examples above project the syntactic and semantic information of the words in reference. The morpheme-iyane in 1(i) and 1(ii) derives ideophones from verbs whereas $-z a$ and $-l a$ in 2(i) and 2(ii) respectively, derive verbs from ideophones. The verbalisers $-s a$ and $-z a$ in 3(i) and (ii) respectively, are used in the derivation of verbs from nouns. The $\mathrm{RHHr}$ is also applicable in isiNdebele as is evident in the preceding examples.

The RHHr has been dismissed as inadequate in dealing with the morphology of English and other related/unrelated languages. Selkirk (1982: 20) notes that the RHHr is inadequate in describing headedness of English word structure mainly because there are some instances where the basic syntactic and semantic information of a word is projected by a prefix rather than a suffix. Consequently, Selkirk (1982: 20) notes that the RHHr "[...] is not universal; it must be stated as part of grammar of English, a parameter which is set for the language, just like the head first/ head last parameter in syntax". There are studies that have been done which disprove Williams' (1981) claim of the RHHr in morphology. Taiwo (2009: 49) states that Williams' (1981) RHHr, and Selkirk's (1982) revision of the same, cannot be generalised to include languages such as Yoruba, where the head is the left-hand member of a word. In isiNdebele, there are cases where the head is a right-hand member of a word, and some cases 
where the head is a left-hand member of a word. The following examples illustrate left-hand headedness in isiNdebele:
4. (i) ukhwetshu
u-khetshu
1a-act of tickingIDEO
'a tick'
(ii) isibane
isi-bane
7-act of flashingIDEO
'a lamp'
e-Lupane
LocPre-Lupanens
'inLupane'
5. (i) eLupane
(ii) eGwanda
e-Gwanda
LocPre-Gwandans
'in Gwanda'
6. (i) useLupane
u-s(e)-e-Lupane
1SM-ASP-LocPre-Lupanens
' $\mathrm{s} / \mathrm{he}$ is in Lupane'
(ii) baseGwanda
ba-s(e)-e-Gwanda
2SM-ASP-LocPre-Gwandans
'they are in Gwanda'

The heads in the above examples are left-hand members of the word constructions contrary to the RHHr's prediction that heads are right-hand members of word constructions. This implies that morphological heads in isiNdebele are either left-hand members or right-hand members of word forms. Although Zwicky (1985), Bauer (1990), and Anderson (1992) posit that heads have no place in morphology, and that there is no need to refer to the head of a word to explain the presence of inflectional and derivational affixes, the present study seeks to explain headedness in isiNdebele extended exponents. If isiNdebele words are either left-headed or right-headed, then it is important to investigate headedness in extended exponence - are the extended exponents left-headed, right-headed, or both?

\section{Data presentation and analysis}

The locative prefix (LocPre) and locative suffix (LocSuf), noun-class prefix, noun deverbaliser morpheme (NDM), and negation markers are treated by Nguni linguists as circumfixes. For example, Pretorius and Bosch (2012), and Kosch (2005) argue that the LocPre and its corresponding LocSuf is a circumfix used in the derivation of locatives from nouns. In the following section, we will present data on isiNdebele locatives. It should be noted that we only discuss the segmentals rather than the suprasegmentals here. As a result, the relation between headedness and the location word-stress in isiNdebele is not discussed in this study.

\subsection{Locativised nouns}

Some locatives are derived from nouns using derivational pairs of affixes. The locative pairs include $e \ldots e n i, e \ldots i n i$, and $o \ldots e n i$. Locativisation involves the affixation of two locative markers to a noun. The first locative marker occurs before the noun as a prefix, while the second locative marker occurs after the noun as a suffix. Consider the following examples:

7. (i) egwalweni

e-tgwalo-eni

LOC-book-LOC

'in the book' (ii) emfuleni

e-tmfula-eni

LOC-river-LOC

'in the river' 
8.
(i) ebantwini
e-abantu-ini
LOC-people-LOC
'in people'
9. (i) okhunjini
o-tkhumbi-ini
LOC-riverbank-LOC
'at the riverbank'

\author{
(ii) ezulwini \\ e-izulu-ini \\ LOC-heaven-LOC \\ 'in heaven' \\ (ii) okhalweni \\ o-tkhalo-eni \\ LOC-waist-LOC \\ 'in the waist'
}

In the examples above, the prefixes and suffixes in reference appear as if they are indispensable. For example, if either the prefix or suffix is absent, we get an ungrammatical word form. One might think that this is an indication that the prefixes and suffixes in reference are instances of continuous affixes which are interruptible, as claimed by Kosch (2005), and Pretorius and Bosch (2012). Compare the examples below with the preceding examples:
10. (i) *egwalo
e-ugwalo
LOC-book
(ii) *ugwaleni
ugwalo-eni
book-LOC
11. (i) *ezulu
e-izulu
LOC-heaven
(ii) *izulwini
izulu-ini
heaven-LOC

The above word forms that start with a locative prefix $e-$ [i.e. 10(i) and 11(i)] are potential isiNdebele forms in the sense that some nouns do not require locative extended exponents. Locativisation of nouns that do not take the extended exponent is achieved by affixing the LocPre to the noun. The ungrammaticality of the constructions above is due to the fact that nominal bases require extended exponents. This shows that these paired affixes appear to behave like circumfixes. However, it should be clarified that they are not circumfixes. With circumfixes, the prefix and the suffix always co-occur (Lieber 1992), whereas with extended exponents the opposite is true. In isiNdebele, you will find that in some circumstances the prefix of the paired affixes can function without the suffix component. We find this in the locativisation of certain nouns. Here are the examples:
12.
(i) ekhanda
e-i-khanda
(ii) ekhaya
e-i-khaya
LOC-5-head
LOC-5-home
'in the head'
'at home'
13. (i) ehlombe
e-i-hlombe
LOC-5-shoulder
'on the shoulder'
(ii) eqolo
e-i-qolo
LOC-5-waist
'on the waist'

In these examples, there are no immediate instances where the suffix is used on its own. This could be evidence that locative extended exponents are left-headed in isiNdebele. Accordingly, one may contend that locative extended exponents are left-headed in isiNdebele because it seems the prefix element can do without the suffixal element, but not vice versa. 


\subsection{Habitual nouns}

The property 'habitual' is usually marked by a prefixal element and a suffixal element in isiNdebele. The habitual (HAB) exponents used in isiNdebele are - so...se and $-m a \ldots s e$. These exponents encircle the nominal base but do not change its class status. Consider the following examples:
14.
(i) usomangase
u-so-manga-se
1-HAB ${ }^{1}$-lie-HAB ${ }^{2}$
'a habitual liar'
15. (i) usomawalase
u-so-ama-wala-se
1-HAB-6-overventuresome-HAB
'an overventuresome individual'
16. (i) umathulase
u-ma-thul-a-se
1-HAB-quiet-FV-HAB
'a very quiet individual'

\author{
(ii) usomhawuse \\ u-so-m-hawu-se \\ 1-HAB-3-jealous-HAB \\ 'a habitual jealous individual'
}
(ii) umanyeyase
u-ma-nyey-a-se
1-HAB-gossip-FV-HAB
'a gossiper'
(ii) umakhalase
u-ma-khal-a-se
1-HAB-cry-FV-HAB
'a cry-baby'

One might think that habitual exponents - so...se are indispensable in isiNdebele. Now compare the examples above with the following:
17. (i) *umangase
u-manga-se
1-lie-HAB
'Mr/ Ms lie'
(ii) *umhawuse
u-m-hawu-se
aug-1-jealos-HAB
'jealous'
18. (i) usomanga
u-so-manga
1-HAB-lie
'a father of lies'
(ii) usomhawu
u-so-um-hawu
1-HAB-3-jealous
'a father of jealous'

The examples in 17 and 18 illustrate that the use of one element of the pair in the absence of the other element leads to the generation of ungrammatical word forms. The examples 17(i) and 17(ii) are ungrammatical while 18(i) and 18(ii) are grammatical but differ slightly in meaning with those in 17(i) and 17(ii). The former can be said to be variants of the latter. In present-day isiNdebele, the paired affix - so...se is hardly used. The most words that are used, if not the only words, are the ones in example 14(i) and (ii).

Moreover, there are some $-s \mathrm{~S}$ - noun forms that do not make use of the $-s e$ suffix. These noun forms include the following:

\footnotetext{
${ }^{1}$ Prefix of a paired affix.

${ }^{2}$ Suffix of a paired affix.
} 
19
(i) usomabhizimusi
u-so-amabhizimusi
1a-HAB-6-business
'a business person'

(ii) usozikhundla

u-so-izikhundla

1a-HAB-8-position

'a person with a plethora of positions'

It seems -so- can function independently of the suffix -se, as is evident in the examples above. These examples further point to the fact that habitual extended exponents are also left-headed, like locativisers, and that extended exponents are not instances of one morpheme.

\subsection{Negation markers}

Negation markers do not change the grammatical class of a base although they do alter its meaning. Negation in isiNdebele is usually done with inflectional pairs. Negation exponents in isiNdebele include $-n g a \ldots i, k a / a \ldots i, k a / a \ldots a n g a, k a / a \ldots o$, and $k a / a \ldots o n g o$. The present-tense negation morphemes are $-n g a \ldots i, k a / a \ldots i$, and $k a / a \ldots o$. Consider the following examples:

\begin{tabular}{|c|c|c|c|c|c|}
\hline 20. & $\begin{array}{l}\text { ungadli } \\
\text { u-nga-dl-i } \\
\text { 1-NEG-eat-NEG } \\
\text { 'do not eat' }\end{array}$ & (ii) & $\begin{array}{l}\text { kabadli } \\
\text { ka-ba-dl-i } \\
\text { NEG-2SM-eat-NEG } \\
\text { 'they are not eating' }\end{array}$ & (iii) & $\begin{array}{l}\text { kadlanga } \\
\text { ka-dl-anga } \\
\text { NEG-eat-NEG } \\
\text { 's/he did not eat' }\end{array}$ \\
\hline (i) & $\begin{array}{l}\text { ungahambi } \\
\text { u-nga-hamb-i } \\
\text { 1-PR-go-NEG } \\
\text { 'do not go' }\end{array}$ & (ii) & $\begin{array}{l}\text { kahambanga } \\
\text { ka-hamb-anga } \\
\text { PR-go-NEG } \\
\text { 's/he did not go' }\end{array}$ & (iii) & $\begin{array}{l}\text { kahambi } \\
\text { ka-hamb-i } \\
\text { PR-go-NEG } \\
\text { 's/he is not going' }\end{array}$ \\
\hline (i) & $\begin{array}{l}\text { ungatsho } \\
\text { u-nga-tsh-o } \\
\text { 1-NEG-say-NEG } \\
\text { 'do not say' }\end{array}$ & (ii) & $\begin{array}{l}\text { kabatshongo } \\
\text { ka-ba-tsh-ongo } \\
\text { NEG-2SM-say-NEG } \\
\text { 'they did not say' }\end{array}$ & (iii) & $\begin{array}{l}\text { kabatsho } \\
\text { ka-ba-tsh-o } \\
\text { NEG-2SM-say-NEG } \\
\text { 'they do not say' }\end{array}$ \\
\hline
\end{tabular}

Verbs that end with the vowel $-o$ take the paired affix $a / k a \ldots o$ and $a / k a \ldots o n g o$, depending on tense. The dominant negation paired affixes are $a / k a \ldots i$ and $a / k a \ldots a n g a$. The initial and the terminal elements of negation exponents are, arguably, not always mutually obligatory in all circumstances. The fact that the suffixes $-i$ and -anga are used in both the indicative negative (with prefix $a_{-}$) and in the participial negative (with prefix $-n g a-$ ) is a clear indication that negation is expressed by extended exponence in isiNdebele. Moreover, negation suffixes are suppressed in the negation of passivised verb forms, which could indicate that the negation function is usually expressed by two realisations that are not mutually obligatory. A passive morpheme seems to block the terminal element of the negation exponent. As a result, a negated passive form ends with a terminal vowel $-a$ instead of either negation suffix $-i$ or $-o$. Consider the following examples:
23. (i) ungatshaywa
u-nga-tshay-w-a
1-NEG-beat-PASS-FV
'do not be beaten'
(ii) ungadletshwa
u-nga-dleph-w-a
1-NEG-scratch-PASS-FV
'do not be scratched'


24. (i) kabathenjwa
ka-ba-themb-w-a
NEG-2trust-PASS-FV
'they are untrustworthy'

25. (i) kazondwa

ka-zond-w-a

NEG-hate-PASS-FV

'he is not hated'
(ii) kabuzwa
ka-buz-w-a
NEG-question-PASS-FV
' $\mathrm{s} /$ he is not questioned'
(ii) kakhonzwa
ka-khonz-w-a
NEG-worship-PASS-FV
'he is not worshipped'

The verbal forms above are negated although they end with a final vowel $-a$ instead of an expected second negation marker that usually assumes the terminal position in verbs. This could mean that a negation exponent is not a single affix, and that negation involves prefixation and concomitant suffixation.

Moreover, multiple negation markers do occur in negated nominal predicates, and in relativised negative nominal predicates. Negation is expressed by a single negation marker in the constructions in reference. Consider the following examples:
26. (i) muhle
mu-hle
(ii) kamuhle
ka-mu-hle
Neg Pr-1AGR-beautiful ${ }_{N S}$
'she is not beautiful'
1AGR-beautiful ${ }_{\mathrm{NS}}$
'she is beautiful'
27. (i) ibanzi
i-banzi
9SM-widthNS
'it is wide'
(ii) kayiqatha
ka-yi-qatha
Neg Pr-9SM-widthNS
'it is not wide'
28. (i) ongamuhle
a-nga-mu-hle
Rel-NEG-1AGR-beautyNs
'who is not beautiful'
(ii) ongaqatha
a-u-nga-qatha
Rel-1SM-NEG-beautyNs
'who is not fat'

The preceding examples indicate that negation can be marked by a single marker (the prefixal component) which might also imply that the negation extended exponents are left-headed just like locative exponents.

\section{$5.4 \quad$ Nominalisation}

Nouns may be derived from other parts of speech by affixing the nominaliser extended exponents. Nominal extended exponents are employed in the nominalisation of verbs. The constructed forms are personal/impersonal nouns (Doke 1931: 63), agentive nouns (Spencer 1991: 84), and deverbative nouns (Matambirofa 2001: 48).
29. (i) -buz-a
askvR-FV
'ask'

(ii) um-buz-o

CL3-askvR-NDM

'a question' 
30.
(i) -fis-a
wishvR-FV
'wish'
31. (i) -hamb-a
travelvR-FV
'travel'

\author{
(ii) isi-fis-o \\ CL7-wishvr-NDM \\ 'a wish' \\ (ii) isi-hamb-i \\ CL7-travelvR-NDM \\ 'a traveller'
}

The prefixes and suffixes in bold in the preceding examples express nominalisation. One might think that nominalisation is expressed by circumfixes in isiNdebele. However, the nominalisation of ideophones indicates that the noun-class prefix can express nominalisation without being aided by the nominaliser suffix. Consider the following examples:
32. (i) ukhwetshu
u-khwetshu
(ii) isibane
1 -action of ticking
'a tick'
isi-bane
7-of flashing light
'a light'

If the terminal exponents of nominalisers were always co-occurring with their prefixal exponents, we could be talking about circumfixes in isiNdebele. Nonetheless, the absence of the suffix component in the preceding examples suggests that nominalisation is expressed by extended exponence rather than circumfixes, and also that the noun-class prefix heads the nominalised word form. Thus, nominalised nouns are headed by a class prefix.

\section{Conclusion}

This study focused on headedness and instances where a grammatical function is expressed by two non-contiguous morphological realisations in an isiNdebele word form. The study established that morphological heads can either be right-hand members of a word or left-hand members. Verbalisers and affixes that derive ideophones from other parts of speech are immediate examples of right-hand morphological heads in isiNdebele, whereas locative prefixes, noun-class prefixes, and subject markers serve as left-hand morphological heads in the derivation of locatives from nouns, nouns from ideophones, and nominal predicates from locatives. Extended exponents are sometimes used to express location, nominalisation, habitual, and negation in isiNdebele. There are no immediate instances where a suffix of an extended exponent is used in the absence of the prefix, however the opposite is true. The fact that the prefix component of an extended exponent expresses the function, location, habitual, nominal, and negation without the aid of a suffix indicates that extended exponents in isiNdebele are leftheaded or simply that they are more important than their suffix counterparts.

\section{Abbreviations}

$\begin{array}{ll}\text { AGR: } & \text { Agreement } \\ \text { ASP: } & \text { Aspect } \\ \text { CL: } & \text { Noun Class } \\ \text { HAB: } & \text { Habitual Morpheme Marker } \\ \text { IDEO: } & \text { Ideophone } \\ \text { LocPre: } & \text { Locative Prefix }\end{array}$


LocSuf: $\quad$ Locative Suffix

NegPr: $\quad$ Negation Prefix

NS: $\quad$ Noun Stem

PASS: Passive

PR: $\quad$ Prefix

SM: $\quad$ Subject Marker

Rel: $\quad$ Relative

RHHr: $\quad$ Right-Hand Head rule

TV: $\quad$ Terminal Vowel

VR: Verbroot

\section{References}

Anderson, S.R. 1992. A-morphous morphology. Cambridge: Cambridge University Press.

Bauer, L. 1990. Be-heading the word. Journal of Linguistics 26: 1-31.

Caballero, G. and A.C. Harris 2012. A working typology of multiple exponence. In F. Kiefer, M. Ladányi and P. Siptár (eds.) Current issues in morphological theory: (Ir)regularity, Analogy and frequency. Amsterdam: John Benjamins. pp. 163-188. https://doi.org/10.1075/cilt.322.08cab

Doke, C.M. 1931. Textbook of Zulu grammar. Johannesburg: University of Witwatersrand Press.

Harris, A.C. 2009. Exuberant exponence in Batsbi. Natural Language \& Language Linguistic Theory 27(2): 267-303. https://doi.org/10.1007/s11049-009-9070-8

Kosch, I.M. 2005. Discontinous elements in morphology. South African Journal of African Languages 3: 161-170.

Lieber, R. 1992. Deconstructing morphology. Chicago, IL: University of Chicago.

Marušič, F. 2003. 'Aff-STEM-ix': On discontinuous morphology. Ms., Stony Brook University.

Matambirofa, F. 2001. Orature and morpholexical deconstruction as lexicographic archaeological sites: Some implications for dictionaries of African languages. Lexicos 11: 3859. https://doi.org/10.4314/lex.v11i1.51292

Matthews, P.H. 1974. Morphology. Cambridge: Cambridge University Press.

Mbah, B.M. 2012. Circumfixation: Interface of morphology and syntax in Igbo derivational morphology. IOSR Journal of Humanities and Social Science 5(6): 1-8. https://doi.org/10.9790/0837-0560108

Müller, G. 2006. Extended exponence by enrichment: Argument encoding in German, Archi and Timucua. University of Pennsylvania Working Papers in Linguistics 13(1): Article 20.

Pretorius, L. and S. Bosch. 2012. Semi-automated extraction of morphological grammars for Nguni with special reference to Southern Ndebele. A paper presented at The Workshop on Language 
Technology for Normalization of Less-Resourced Languages (SALTMIL8/AfLa2012). Available online: https://pdfs.semanticscholar.org/333f/aad4a44c1d0497b1b7913956cb3885c5e 145.pdf (Accessed 28 March 2019).

Rio-Torto, G. 2002. How much different are the prefixes and the correlative circumfixes in verb-formation? Paper presented at the $10^{\text {th }}$ International Morphology Meeting, 9-12 March 2002, Budapest.

Ruszkiewicz, P. 2003. On the status of infixation and circumfixation. Poznań Studies in Contemporary Linguistics 38 (2002/2003): 133-166.

Selkirk, E. 1982. The syntax of words. Cambridge, MA: MIT Press.

Spencer, A. 1991. Morphological theory: An introduction to word structure in Generative grammar. Oxford: Basil Blackwell.

Stump, G.T. 2001. Inflectional morphology: A theory of paradigm structure. Cambridge: Cambridge University Press.

Taiwo, O. 2009. Headedness and the structure of Yoruba compound words. Taiwo Journal of Linguistics 7(1): 27-52.

Williams, E. 1981. On the notions 'Lexically Related' and 'Head of a word'. Linguistic Inquiry 12(2): 245-274.

Zwicky, A.M. 1985. How to describe inflection. Proceedings of the Annual Meeting of the Berkeley Linguistics Society II. pp. 372-386. Available online: https://journals. linguisticsociety.org/proceedings/index.php/BLS/article/viewFile/1897/1669 (Accessed 28 March 2019). https://doi.org/10.3765/bls.v11i0.1897 